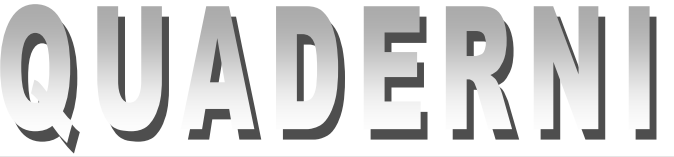

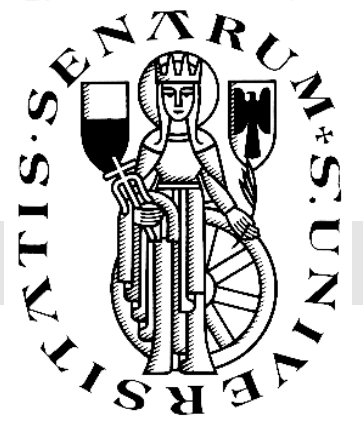

Università degli Studi di Siena

DIPARTIMENTO DI ECONOMIA POLITICA

\section{ALBERTO BACCINI}

Edgeworth on the Foundations of Ethics and Probability

n. 427 - Maggio 2004 


\begin{abstract}
This paper analyses the foundation of utilitarian ethics and theory of probability in the works of Francis Y. Edgeworth. We argue that he pursued an unitary philosophical project, the search for a common epistemological foundation for the social sciences. The common root of the disciplines is the notion of "hereditary experience" derived from Herbert Spencer's work. We suggest that this reconstruction can modify the overall interpretation of Edgeworth's thought.
\end{abstract}

Keywords: F.Y. Edgeworth, Probability, Utilitarianism

J.E.L. classification: B13, B31, B40

Research was supported by funding from MIUR, Programmi di ricerca di rilevante interesse nazionale 2002, project “The role of mathematics in the history of economics" (prot. 2002133491_003)

Alberto Baccini, Dipartimento di Economia Politica, Università degli Studi di Siena 
Whoever happens to look through the bibliography of the works of Francis Ysidro Edgeworth (Baccini 2003) finds himself confronting a very delicate question. Edgeworth began to write at a fairly advanced age, and did not write about economics. His first publication was a note on "Mr. Matthew Arnold on Butler's Doctrine of Self Love”, which came out -when he was 31 years old- in 1876 in Mind, the philosophy and psychology journal founded by Alexander Bain that same year. In 1877 he published privately a short book entitled New and Old Methods of Ethics [hereinafter NOME], followed in 1879 by the article "The hedonical calculus" in Mind (Edgeworth 1879), which was included in Mathematical Psychics [hereinafter MP] two years later. Edgeworth then began to write about philosophy and utilitarianism, applying mathematical instruments to these problems. Probably only after meeting William Stanley Jevons did he understand that the problem was economics, and he had to deal not only with the maximisation of collective utility, but also with the exchanges between self-interested individuals. ${ }^{1}$ This topic is the subject of MP, which was also published privately in 1881. From that moment on, Edgeworth began to write about probability and statistics. In 1886 he returned to economic subjects in a paper (Edgeworth 1888), in which there was no connection with the economical calculus of MP. He wrote the methodological Address to Section F of the Royal Society in 1889: it was dedicated to the question of the application of mathematics to political economy. He returned to the question of exchange only in 1891, in a famous controversy with Marshall (Edgeworth 1891, 1891A).

Many of Edgeworth's interpreters have been amazed by this unexpected change of strategy after 1881. It must have been due to two external circumstances: the frigid welcome given to NOME and MP by economists, and the positive criticism of his work made by Francis Galton, who reportedly advised him to shift his interests to statistics (Stigler 1986; Newman 1987; Mirowski 1994).

The interpretation proposed in this work is that the shifting of attention from ethics to exchange, probability, statistics, and, lastly, to economics is part of a path of research which is the result of a unitary philosophical project: the search for a common foundation for the social sciences. This common foundation consisted of the

\footnotetext{
${ }^{1}$ Jevons was introduced to Edgeworth by the psychologist James Sully (1842-1923), who became a friend of Edgeworth's in the mid-1870s (Sully 1918: 164 cited in Newman, 1987:88).
} 
identification of a unitary epistemological basis, which involved the possibility of utilising cognitive material of the same species, although of a different genus, to resolve the problems of ethics, probability, statistics and lately economics. This reconstruction of the Edgeworthian research programme can substantially modify the overall interpretation of his thought, dispelled around the two stereotypes of the misunderstood precursor, and of the writer with a difficult style, unsuitable to the writing of treatises, always favourably disposed to discuss the ideas proposed by others, but incapable of proposing clearly and coherently a view of the problems and of their solutions.

This work proposes to analyse the subject of the foundation of utilitarian ethics in NOME, and to demonstrate that the philosophical process at the basis of the foundation of ethics is the same one that Edgeworth applied to probability.

\section{The epistemological foundation of ethics}

About one half of the 92 pages of NOME are dedicated to a discussion of the works by Alfred Barratt; and Henry Sidgwick. Peter Newman (1987) affirms that the reasons for economists being interested in NOME begin on page 35, where utilitarianism is discussed. Howey (1960) places NOME in the context of the British philosophical debate on ethics, and stresses a relevant novel element: Edgeworth introduced arguments into the debate that were taken from the research tradition of psycho-physics. Mirowski (1994) used NOME against the image of Edgeworth as a docile anticipator of modern orthodoxy.

For the purposes of our reconstruction it is interesting to contextualise NOME within the debate on utilitarianism in Great Britain during the second half of the $19^{\text {th }}$ century, when the evolutionist perspective had already acquired an important space in ethical reasoning. In the first 35 pages of NOME, Edgeworth deals with the topic of the epistemological foundation of ethics: the problem is that of exploring the available paths for founding, justifying or explaining choices and normative judgements. Also in NOME, the general objective of utilitarian ethics is the maximisation of social welfare. The goods subject to maximisation are defined on the basis of the notion of pleasure (and pain). Pleasures differ from each other only on a quantitative basis. We are, therefore, on the side of hedonism. The normative proposals contained in NOME are 
not a part of a general philosophical system, according to the perspective indicated by Sidgwick on the autonomy of ethics. Edgeworth, however, deals with the way in which it is possible to learn (and measure) the materials on which the argument on ethics is built (Lecaldano 1995).

The basic problem in the first part of NOME is the definition of a synthesis capable of putting together the antithetical positions of Barratt $(1869,1877)$ and Sidgwick (1874). The question is whether - as in Barratt's perspective - pleasure and pain are to be considered the only reasons for voluntary actions and whether the action is proportional to their intensity, or else - as with Sidgwick - the desire for something is proportional to the idea of its pleasantness. Indeed, it is a question of the conflict between a reductionist view - that of Barratt - and a non-reductionist one - that of Sidgwick - regarding the question of motivations: whether they can be reduced to simple contractions (searching for pleasure) and irritations (fleeing from pain) of our nervous system, or whether instead they are relative to the sphere of consciousness.

Discussion of the question is organised, following Barratt, into three different perspectives: physical (NOME: 2-5), introspective (NOME: 5-7), and intuitionistic (NOME: 8-10).

Barratt maintained that all human actions have their origin in pleasure, understood as a pure physical phenomenon. Edgeworth was fascinated by the idea, and was favourably disposed to accept that a physical origin of human actions exists. However, he considered it difficult to confirm that all actions derive directly from pleasure: in fact, individuals experiment and attribute a difference between reflex actions and volitive actions, and between hedonistic preferences and non-hedonistic preferences. Barratt ended by confirming, instead, ${ }^{2}$ according to Edgeworth, that "nonhedonistic action is impossible” (NOME: 186). Edgeworth declared that he was not completely convinced by Barratt's position, from either a physical or an introspective point of view, and sought elements capable of leading to a synthesis with Sidgwick's one. The main point of attack was Barratt's admission "that habit is an exception to, a modification of, the general hedonistic rule” (NOME: 8).

\footnotetext{
${ }^{2}$ Edgeworth said that Barratt glosses over this affirmation, and commented, "The labours of the students are rewarded with a paper-money of definition, which after all may not be cashed at the bank of experience" (NOME: 186).
} 
Barratt's construction - Edgeworth said - can be considered to be a founding part of a new utilitarian ethics if appropriately modified with the introduction of two postulates. The first, "guaranteed by the authority of innumerable savants”, establishes "the interdependence of body and mind" (NOME: 10). This interdependence is manifested in the fact that phenomena which have to do with sensations are conjoined to each phenomenon of thought. A movement in the material substrate of the mind itself is associated with every mental phenomenon: ${ }^{3}$ "to every phenomenon of reflection are conjoined certain phenomena of sensation: so that definite physical phenomena (which Mr. Barratt, if he please, and if he is consistent, may call pleasure ${ }^{4}$,) are the cause of all human action.” (NOME: 10)

The second postulate adds that "all actions have as more or less remote antecedent, experienced pleasure; experienced, either by the agent himself, or by his ancestry.” (NOME: 11)

It may be useful to clarify the significance of this second postulate: the search for pleasure and the flight from pain can be explained in relation to the fact that, in the nervous system, certain inter-relations are constituted that associate pleasure and pain to previous experiences of pleasure and pain more or less remote in time. There are two types of these experiences: experiences already had by the individual during previous periods of his life; and experiences handed down to the individual by the species to which he belongs, through the physical connections internal to the structures of the nervous system, which he inherits from the species. Both these postulates (unquestionably the second) find their ultimate origin in Principles of Psychology by Herbert Spencer (1870). In relation to the first postulate, it is sufficient to recall that for Spencer, just as for Alexander Bain (Raffaelli 2003: 19), as well for Edgeworth, the

\footnotetext{
${ }^{3}$ Edgeworth's habit of justifying a postulate on the basis of a reference to authority is to be noted. The authorities cited are the psychologists Theodor Gustav Fechner and Wilhelm Wundt (for a discussion of their work within the history of statistics, cf. Stigler 1978: 239-261; cf. also, respectively, Porter 1986: 245-246 and 57-58; and the physicist John Tyndall, for whom cf. Porter 1986: 202-204.

${ }^{4}$ Edgeworth refers to the physical pain of Barratt's theory, by utilising italics, as in the quotation (NOME: 3).

${ }^{5}$ And continues in his desire for an extreme synthesis: "the cause also, or the Baconian form, of pleasure as a conscious feeling, the end of the pure egoist and not only of that state of consciousness, but of every species of non-hedonistic preference (if such there be), of various states associated with various names, $\alpha \gamma \alpha \theta$ òv [good] , $\varepsilon v \varepsilon \rho \gamma \varepsilon ı \alpha$ [an Aristotelian term which indicates force, efficacy or energy, in this case, of an argument], duty, practical reason, moral sense, the affection of Butler, the sentiment of Hume, the reason constituted desire of the Hegelian, and that fixed idea, which supports the sympathy which crowns the edifice of Bain's utilitarianism." (Edgeworth 1877: 10)
} 
elementary movement of the human organism is caused by the search for pleasure or by the flight from pain.

The question is more complex as far as the second postulate is concerned, since Edgeworth reinterprets ${ }^{6}$ in terms of pleasure/pain and of experiences of pleasure and pain a remark that Spencer made more generally in relation to the origin of knowledge (NOME: 12 note 2). According to Spencer human beings are born with a nervous system inside of which connections handed down from the species are defined; a human being is not a tabula rasa. ${ }^{7}$ These combinations/connections determine for the individual a "preparedness to cognize” (Spencer 1870: 469), inherited by the species: "Those who contend that knowledge results wholly from the experiences of the individual, ignoring as they do the mental evolution which accompanies the autogenous development of the nervous systems, fall into an error as great as if they were to ascribe all bodily growth and structure to exercise, forgetting the innate tendency to assume the adult form.” (Spencer 1870: 469)

For Spencer, the nervous system was something organic, subject to evolution, which incorporates a priori knowledge within its structure. The individual experience not only furnishes the concrete material at the basis of all thoughts, but without it the organised structures of the nervous system would not, on their own, give rise to knowledge: "These pre-determined internal relations, though independent of the experiences of the individual, are not independent of experiences in general: they have been determined by the experiences of preceding organisms. [...] [T]he human brain is an organised register of infinitely-numerous experiences received during the evolution of life, or rather, during the evolution of that series of organisms through which the human organism has been reached.” (Spencer 1870: 471)

At this point, we have the elements for reasoning about the origin of the second postulate introduced by Edgeworth: it is based on the "conclusive evidence" (NOME: 11) supplied by Spencer. Applied to the case of ethics, Spencer's idea is translated as

\footnotetext{
${ }^{6}$ Edgeworth considered that he was applying Spencer's thought to a new question, as can be seen in NOME: 11 note 2.

7 "Throughout the animal kingdom in general, the actions are dependent on the nervous structure. The physiologist shows us that each reflex movement implies the agency of certain nerves and ganglia; that a development of complicated instincts is accompanied by complication of the nervous centres and their commissural connexions; ...; and that as we advance to creatures of high intelligence, a vast increase in the size and complexity of the nervous system takes place. What is the obvious inference? It is that the
} 
the individual's “experience of pleasure” and the experience of pleasure handed down to him by the experiences of pleasure of the species. Every action can therefore be attributed either to individual experiences of pleasure/pain or to the experiences handed down to the individual by the species. In this way, it is possible to justify also apparently non-hedonistic actions as referring to an ancestral experience of pleasure and pain. On the basis of these two postulates, Edgeworth was able to overcome one of the most problematic consequences of Barratt's work, i.e. the one relative to the impossibility of non-hedonistic actions, ${ }^{8}$ which can now be attributed to the association with "the common pleasure of a remote ancestry" (NOME: 12). In particular, Edgeworth maintained, “non-hedonistic preference is ancestral habit” (NOME: 7, 25).

We have already noted that the proposal of a synthesis of the positions of Barratt and Sidgwick was based on the idea shared by both authors of habit as an exception to the hedonistic rule. On the basis of Spencer's interpretation, Edgeworth proposed to interpret non-hedonistic preferences as being based on ancestral experiences of pleasure: “all non-hedonistic action (if such there be) is of the nature of (personal, or) ancestral habit” (Edgeworth 1877: i). ${ }^{9}$

The notion of ancestral habits thus acquired an important role, not only from the point of view of the epistemological foundation of ethics, but also for the definition of the role of ethical propositions. It served him in fact in order to justify the idea of $a$ priori imperatives which pure hedonism is not able to account for.

"The observations of Herbert Spencer on a priori propositions generally, mutatis mutandis and taken in connection with his chapters on feeling and volition, render it probable that the a priori imperative of the practical reason are of nature of ancestral habits." (NOME: 12)

It served also to delimit the notion of moral imperative which "is bounded by physical possibility. [...] It is vain, then, to recommend a course of action, not tending to the pleasure of the agent as right, reasonable, \&c., if it can be shewn that never in any

ability to co-ordinate impressions and to perform the appropriate actions, always implies the pre-existence of certain nerves arranged in a certain way.” (Spencer 1870: 468)

${ }^{8}$ Edgeworth judged as an acrasia (from the Greek, meaning mixture) the use on Barratt's part of the saying video proboque deteriora sequor as as a proof of the impossibility of non-hedonistic actions. Barratt interpreted the motto in the sense that, while it is true that a knowledge of good is not an incentive to action, nevertheless the choice always falls on what is most desired; and what is most desired is that which causes most pleasure (Edgeworth 1877: 12). 
past stage of evolution could such actions have tended to the pleasure of the agent sufficiently to produce an ancestral habit.” (NOME: 13)

Subtended to the notion of physical possibility and of ancestral habits is, once again, the notion of experience. In fact, this interpretation of physical ethics of Barratt's "presume[s] an experiential theory of the origin of knowledge - both that general ethical propositions are given by experience personal or ancestral, and that the ethical predicate (right, duty, \&c.) is generated out of simpler ideas or feelings, in the course of evolution, by a sort of mental chemistry. But such a theory involves, as Mr. Sidgwick has shewn, no prejudice to the intuitive methods of morals [...]. And [...] the experiential theory of knowledge has been freed from many difficulties by the qualifications introduced by Herbert Spencer." (NOME: 19)

In this way, Edgeworth closed the circle of his reasoning to the point of defining an experiential or - if you like - physical basis for ethics. In the foundation of moral philosophy, ancestral habits thus serve to have legitimately represented, in a utilitarian context, many forms of real behaviour, such as non-hedonistic actions, which it would be impossible to take into account. All of this by means of an expansion of the domain of the experience of pleasure, extended to include the one carried out by the species and handed down genetically to successive generations. Moreover, personal or ancestral experience also ends up by representing the physical possibility of defining moral imperatives, since the moral imperative derives in any case from a remote or ancestral experience of pleasure. Conceivable, possible and pursuable moral imperatives are those deriving from a present or ancestral association with experiences of pleasure.

\section{The epistemological foundation of probability}

In the years between 1883 and 1885, Edgeworth began his Treatise on Probabilities (hereinafter called TP) - which is not a real treatise, but a forty-year-long series of articles published mostly in the Journal of The Royal Statistical Society. ${ }^{10}$ And he began to write it, as he had done for ethics, starting from the epistemological foundations of probability. While in NOME Edgeworth had supplied the

\footnotetext{
${ }^{9}$ It must be noted that in Barratt, the notion of habits is a Humian derivation. Barratt, A., "Physical Ethics”, Mind, 1877: 175.

${ }^{10}$ On the existence of the treatise, Baccini 1997; 2001. For the bibliography, Baccini 2003.
} 
epistemological bases of ethics, and had supplied the basic material on which to form normative judgements, for probability he had to deal with the subject of the epistemological bases of probable knowledge. This second research path had important precedents in the English tradition of the philosophy of probability, and Edgeworth prepared to apply to it the same philosophical instrumentation that he had applied to ethics. $^{11}$

The reference text for Edgeworth's TP is The Logic of Chance by John Venn, ${ }^{12}$ which canonically systematised the frequentist theory of probability. ${ }^{13}$ In the frequentist tradition, probability is empirically measurable as the relative frequency of occurrences. According to Venn, the probability of an event presupposes the existence of an adequately long series of events belonging to at least two distinct classes, in order to possess certain characteristics or not. A series is defined in reference to a large number of events/objects which are not necessarily temporally ordered. It combines the irregularity of the individuals with the regularity of the aggregate (Venn 1888: 4), and represents "the ultimate basis upon which all the rules of Probability must be based" (Venn 1888: 2). To determine the existence of the series and the numerical proportion of their characteristic properties, it is necessary to resort to experience:

"Experience is our sole guide. If we want to discover what is in reality a series of things, not series of our own conceptions, we must appeal to the things themselves to obtain it, for we cannot find much help elsewhere. [...] When we thus speak of 'experience' we mean to employ the term in its widest signification; we mean experience supplemented by all the aids which inductive or deduc tive logic can afford.

\footnotetext{
${ }^{11}$ An analogy that is driven to the point of a metaphor: as far as physical ethics is concerned, Edgeworth wrote: "It is unnecesary to pursue these suppositions further, far beyond the limits of scientific hypothesis. Physical Ethic is seen to be a frail edifice resting on a secure basis, the fragility of the edifice rapidly increasing with its height." (Edgeworth 1877: 17-18); for probability: "I would not undertake to indicate the exact point at which the sustaining forces are applied to that substructure, which, in Mr. Venn's words, «is not so much to be compared to the solid foundations of an ordinary building as to the piles of the houses of Rotterdam, which rest somehow in a deep bed of soft mud»." (Edgeworth 1884: 235)

${ }^{12}$ The first edition is of 1866; the second, the one utilised by Edgeworth, is that of 1876 (not of 1879, as results from the misprint in Baccini 2001: 746). In writing a critique of the third edition of 1888 in the Journal of Education, Edgeworth wrote, "He [Venn] is the founder of a new school [...]. Where the older theorists were content with abstract general reasoning, the younger generations insist upons specific experience. Dr. Venn has a Baconian horror of reasoning down from carelessly assumed general notions. [...] He undoes the work of his mathematical predecessors. Laplace had treated the theory of Probabilities as le bon sens réduit au calcul. Dr. Venn's restatement of the doctrine may be described as le calcul réduit au bon sens. [...] We have said enough to show how important is Dr. Venn's work, how indispensable to a right use of the calculus.” (Edgeworth 1888A: 251))

${ }^{13}$ On Venn and the frequentist theory, cf. Baccini 2001 and the bibliography cited therein.
} 
[...] the series we employ are ultimately obtained by experience only." ${ }^{14}$ (Venn 1888: 74-75) ${ }^{15}$

Here, it is of interest to dwell on the consequences of considering experiences to be the only instrument capable of furnishing the cognitive bases of probability. What occurs, and which we shall debate a little further on, is that every cogent notion of $a$ priori probability disappears, and it is therefore impossible to demonstrate the Bayes' theorem (and the rule of succession). Indeed, a radical experiential basis strongly limits, so to speak, the extent of the theory. It may be useful to give a better explanation of this point: in the $19^{\text {th }}$-century debate, a priori probability meant the probability preceding every type of individual experience, that for example which assigns equal probability to every outcome in a game of chance. It is the probability that derives from the principle of sufficient reason or, to use the Keynesian expression, the principle of indifference. For Venn, the idea of justifying an attribution of probability of this type is not coherent with the semantic basis of probability: probability values are assigned in relation to experience; a priori probability, instead, finds its origin in an epistemic judgement: in the absence of evidence to the contrary, all events are considered as equally probable (in the long term). According to Venn, this is a different probability from the one deriving from experience of series, which cannot be confused with it. ${ }^{16}$ In The Logic of Chance, Venn dedicates an entire chapter to showing that a priori must be interpreted as a simple label for identifying the ideal conditions in which certain results are produced in games of chance. In the case of tossing a coin, for example, the a priori idea is linked to the conditions producing the results, i.e. to the ideal conditions for which the desired results are produced. Thus, to define the probability that heads will come up as a priori means utilising a synthetic formula for understanding all the objective conditions for which it can be imagined that a certain result is produced: that the coin has not been manipulated, that it has been tossed using criteria of chance, etc. In this sense, the

\footnotetext{
${ }^{14}$ It is interesting to note that the introduction of the notion of experience as justification for the entire construction of the theory of probability represents a radical turning point for the coeval debate, dominated by the figures of Laplace and de Morgan (Dessi, 1988). Venn spent many pages arguing in detail, both against the classical view of probability and also again the subjectivistic interpretation, raising specifically philosophical objections against the former, and showing how the latter ends by seriously modifying the scientific status of the probability theory.

${ }^{15}$ Venn superimposed on this experiential basis a "more subjective" interpretation, which is not relevant for our reasoning and for which the reader may refer to Baccini (2001).

${ }^{16}$ The same reasoning could be made in relation to the monadic and dyadic notions of probability. Frequentist probability is dyadic; a priori probability is monadic (Cohen 1989).
} 
notion of a priori is completely legitimate, but is depleted of much of its importance because it is reduced to the notion of "ideal series" - which is not applicable to cases different from games of chance, seeing that "it is they alone which show the requisite characteristics with any close approach to accuracy” (Venn 1888: 95).

Thus limited, the a priori probability is no longer capable of furnishing the $a$ priori or initial probabilities which are utilised in Bayes's theorem.

The theory of probability contained in Edgeworth's TP can be placed against this background. From all the definitions contained in TP, it is highly evident that Edgeworth had in mind statistical or, if you prefer, frequentist probability. Taking up a suggestion of Venn's, Edgeworth referred probability to two different spheres, one objective, relative to the frequencies observed in a certain phenomenon, and one subjective, relative to the mental condition associated with those frequencies:

"Probability may be described, agreeably to general usage, as importing partial incomplete belief [...] as differing somehow in degree from perfect belief or rather credibility. [...] Thus the object of the calculus is probability as estimated by statistical uniformity.” (Edgeworth 1884: 223)

Is is interesting for us to dwell on the objective part, ${ }^{17}$ i.e. the reflections on the frequentist nature of probability. ${ }^{18}$ Edgeworth's objective was to remove the limitations on the theory imposed by Venn without forgoing the frequentist foundation.

To give an account of the Edgeworthian strategy, it may be useful to follow the re-interpretation of classical and frequentist probability as synthesised in the following passage, by comparing it with the famous Laplacean definition:

"The probabilities with which the calculus deals admit generally of being measured by the number of times that the event is found by experience to occur, in proportion to the number of times that it might possibly occur.” (Edgeworth 1911: 376)

In Laplace’s definition,

\footnotetext{
${ }^{17}$ The reader is referred to Baccini 1997, 2001 as regards the subjective part.

${ }^{18}$ Dozens of quotations contained in TP could be assembled which testify to this view of probability. However, it may be useful to recall at least two of them: "The Calculus of Probability is concerned with the estimation of degrees of probability; not every species of estimate, but that which is founded on a particular standard [...]. That standard is the phenomenon of statistical uniformity [...]" (Edgeworth 1884: 223); "the probability of an event is measured by the frequency with which it has occurred in past experience." (1899: 208). If anything, we must wonder how an idea different from this one occurred to several modern interpreters (Mirowski 1994; McCann 1994).
} 
"le rapport de [le nombre de cas favorables à l'évènement dont on cherche la probabilité] à celui de tous les cas possibles, est la mesure de cette probabilité qui n'est ainsi qu'une fraction dont le numérateur est le nombre des cas favorables, et dont le dénominateur est le nombre de tous les cas possibles.” ${ }^{19}$ (Laplace 1814: 7)

Two points of interest emerge from the comparison: the different nature of probability, and the interpretation of the notion of equipossibility. For Laplace probability is a characteristic of the analysed object and of its every individual outcome. In tossing a dice, for example, probability is attributed to every individual outcome of a single toss and, through Bernoulli's theorem, to an infinite series of tosses. For Edgeworth probability is a meta-object defined on the basis of a function of measurement - dependent on our experiential knowledge - on external objects. As in the frequentist tradition, probability cannot be attributed to individual events, but only to series in Venn's sense; in tossing a dice, for example, probability can be attributed to series of tosses, and not to a single toss (Baccini 2001).

To clarify the interpretation of the notion of equi-possibility, it is useful to start from considerations of the classical theory of probability. Differently from Venn, Edgeworth maintained that classical probability and frequentist probability are not "so diametrically opposite as might appear at first glance” (Edgeworth 1911: 377 §2). ${ }^{20}$ In fact, both must reply to the same question: on what evidential basis are the facts utilised to measure probability identified (Edgeworth 1911: 376)? To be able to reply reasonably, the two versions must be modified and softened: the classical view, through the introduction of the possibility of modifying "in accordance with actual experience" the concrete applications of the Laplacean rule (Edgeworth 1911: 377 §3); ${ }^{21}$ the

\footnotetext{
${ }^{19}$ Or, again: « La probabilité d'un évènement est le rapport du nombre de cas qui lui sont favorables au nombre de tous les cas possibles, lorsque rien ne porte à croire que l'un de ces cas doit arriver plutôt que les autres, ce qui le rend, pour nous, également possible.» Laplace 1886 : 181.

20 "The ground of probability is sought in the observed fact of a class or «series» such that if we take a great many members of the class, or terms of the series, the terms thereof which belong to a certain assigned species compared with the total number taken tends to a certain fraction or limit.” (1911: 377)

${ }^{21}$ The modification of classical probability can be illustrated with reference to an experiment by Walter F.R. Weldon (Edgeworth quotes Weldon by Pearson 1900A: 168; on Weldon, see Pearson 1906), who conceals behind his apparent reasonableness a very harsh attack on the Laplacean view. The fact that in tossing a dice, the probability of throwing a five or a six is 0.3 is, at least approximately, to be attributed to the fact that five and six are faces of an almost perfect cube. Weldon has shown that for several die used in his experiment, the probability of 5 or 6 was 0.3377 , instead of the theoretical one. Since this error is not predictable before having carried out the experiment, followers of Laplace must accept the $a$ posteriori correction that, for the particular set of die used by Weldon, the probability of throwing a 5 or a 6 is 0.3377. Indeed, this Edgeworthian proposal of correcting the Laplacean position involves: (i) the
} 
frequentist view, with the idea in consequence of which "the series which is regarded as the empirical basis of probability is not a simple matter of fact” (Edgeworth 1911: 377 $\S 3)$, since they imply the interaction of the facts with a subject which knows them experientially.

Edgeworth thus distinguishes two forms of equi-possibility. In the case of games of chance - in the absence of evidence to the contrary - application of the Laplacean rule is correct: it is based, not on an a-priori type of realism (equi-probability is, so to speak, incorporated in the faces of the dice), but on the humane experience relative to games of chance. In the case of series - which posed problems in Venn's construction the idea of equi-possibility must be interpreted once again with reference to experience. But for this, it is necessary to enlarge the domain of experience with respect to the high and dry position to which Venn had relegated it. Let us give the word to Edgeworth in two surprisingly clear quotations:

"Such a principle, which I will not attempt to formulate precisely, might be rested upon Experience: Induction and Analogy, upon which Mr. Venn rests the proof of his «series». But this experiential basis must be made wider than Mr. Venn admits. It must cover not only experiments with coins and dice, but an indefinite number of instances in which the statistical ratio of real occurrences is what we conceive to be reasonable, what we find difficult to conceive other than it is.” (1884B: 158)

And again:

"I only contend that Mr. Venn [...] has not made the foundation wide enough, and that therefore he is unable to carry up the structure to the full height of generality. He is unable to rise an axiom of equal distribution of quantity in general, above the view that, in the absence of any such [specific] information, we are entirely in the dark.”(1884B: 160-161)

To clarify this, Edgeworth was to use the same examples several times in TP. The most recurrent one - and the one which appears first chronologically - regards the measurement process for physical sizes: the a priori probability that a certain value of the measurement is correct is equal to that of any other value within a certain interval (Edgeworth 1884: 231; 1884A: 255; 1911: 377 §7). In the case of a barometric

possibility of modifying equi-possibility ex-ante on the basis of ex-post empirical evidence for particular cases, without this impairing the general validity of the ex-ante distribution; (ii) the limitation of the Laplacean view to general cases in which empirical evidence is momentarily unavailable (Edgeworth 1911: 377 §3). 
measurement, for example, certain pressure values do not have the same probability of being registered with respect to others: the postulate required is that the equi-probability among the possible values exists with respect to a small interval, not among very different or very extreme values (Edgeworth 1911: 377 §7). A second example concerns a universally-shared mathematical experiment relative to the distribution of figures in the numbers "which come under our notice (1884B: 159) or in the expansion of $\pi$ (Edgeworth 1884: 229-230; 1911: 378 §10; 1921: 83; 1922B: 486-487). In both cases, it is expected, "with the conviction that greatly exceeds every specific verification" (Edgeworth 1911: 378), that a figure appears in the same proportion as every other one, or that any figure whatsoever can be found in every position: the rule is the randomness of the appearances (Edgeworth 1922: 261). In this sense, the experiments of R.A. Proctor (1874: 100) and of Edgeworth himself (Edgeworth 1884B: 159; cf. also the long note in 1922C: 487), on the basis of the calculations of the value of $\pi$ by William Shanks (1853) only fortify a generalised conviction.

Thus, according to Edgeworth, assertions of a priori probability have sense not only in reference to games of chance:

"The preceding example may suggest that the evidence of propositions of the sort under consideration, although inductive, may be of that species of copious, intimate, almost unconscious, perhaps hereditary, induction on which some rest the axioms of mathematics.” (1884B: 159, italics added)

and, more precisely:

"I submit that the «intellectual» probability ${ }^{22}$ is not essentially different from the «material», but only consists, so to speak, of a more diffused sort of matter; that the change which is made is not from experience into dreamland, but from a particular to a more general sort of experience. [...] The ground of this belief is a very wide experience, perhaps, of the unconscious and even ante-natal species which some prefer to call intuitive knowledge. At any rate the belief is supported by actual experience [...].”(Edgeworth 1884: 229-230, italics added)

The references to forms of experiential knowledge which are handed down through heredity - and which belong to the species before they belong to the individual - are evident in the two preceding quotations. It is through this hereditary memory of past experience that it is possible to consider a priori probability as being solidly and 
experientially founded. To avoid abandoning the solid ground of experience and ending up in the dreamland, Edgeworth then repeated for probability the same operation that he had perfected in NOME. He did it, as usually in his style, implicitly, that is, without a detailed exposition, by relying on the adjectives that accompany "knowledge" and “experience”.

From what we have seen so far, it seems reasonable to contend that the operation carried out for ethics in the 1877 book, and what he asserted seven years later in "The Philosophy of Chance" and "Chance and Law" is to be attributed to the same philosophical project which was aimed at enlarging, on an experiential basis, the narrow limits imposed by the hedonistic tradition and by the frequentist tradition on, respectively, ethics and probability. It also seems reasonable to contend that both operations find their origin in the Spencerian interpretation of the notion of a priori. $^{23}$

Thus, in 1884, Edgeworth defined a physical-experiential basis on which to found the theory of probability. With respect to the $19^{\text {th }}$-century frequentist tradition and mainly to Venn's Logic, in TP we face a certainly weaker foundation. In fact, in Edgeworth, the ascertainment of a plurality of forms of experience justifies the utilisation of a plurality of notions of probability. This means that, in reference to various phenomena, it is legitimate to use probabilities that are established in a different way. Indeed, Edgeworth did nothing more than extend the range of meanings of probability that can be correctly asserted within an empiristic view à la Venn. While in Venn, as we have seen, the only notion of probability having a right to citizenship makes probability coincide with relative frequency, Edgeworth says that, within the

\footnotetext{
${ }^{22}$ This is George Boole's expression for indicating a priori probability.

${ }^{23}$ In reality, this interpretation is toned down during the course of TE to the point of losing every evolutionist connotation in Edgeworth (1911: 377 n. 17; 397 n. 6 [in the note there is a reference error: it says Mind 1884, instead of Mind 1880]). It should be noted that in both notes, Edgeworth stresses the approval of Karl Pearson, (1900: 146), in which, although in the presence of explicit references to Edgeworth (1884), no quotation by Spencer is found, nor any terminological reference to the evolutionist tradition. It seems indeed that the Humean interpretation is accentuated: a priori probability is now indicated with the expression "unverified probability" (Edgeworth 1911: 377 §6); he talks about "continuous, extensive, almost unconsciously registered experience in pari materia" (Edgeworth 1911: 377 §5) and maintains that "this a priori probability is sometimes grounded on our ignorance; according to another view, the procedure is justified by a rough general knowledge" (Edgeworth 1911: 396). The evolutionist language abandoned in the Encyclopaedia Britannica is resumed in connection with the Keynesian Treatise. In the "Philosophy of Chance" can in fact be read: "I have maintained that the ground of those beliefs is a very wide experience, perhaps of the unconscious and even antenatal species, which some prefer to call intuitive knowledge” (Edgeworth 1922: 266), and it is maintained that this principle is not so distant from the Keynesian principle of indifference, a topic which is returned to in great detail in the following chapter.
} 
same theoretical framework, a probability defined as a priori can also be treated cogently. If it is possible to define a priori probability, values of probability calculated a posteriori - i.e. by resorting to Bayes's theorem - can consequently be accepted. This acceptance depends on the fact that they make reference to different experiences with respect to the relative frequency of phenomena.

\section{Conclusions}

In the text we have argued in favour of the idea that Edgeworth applied the same philosophical project to the foundation of ethics and of probability. In these conclusions, after two incidental considerations, we shall attempt an interpretation of this result within the interpretative perspective suggested at the beginning of the work.

The first incidental consideration regards the resemblance between the path of research delineated for Edgeworth and that of the young Alfred Marshall, collected in his youthful manuscripts and synthesised by Raffaelli (2003). The two authors started from a common interest in the theory of the mind, and had common philosophical sources: Spencer's Treatise on Psychology. They also had common objectives: the building of more or less complex formulas capable of explaining human actions. Their perspectives probably differed: for Edgeworth, at least during the first phase, interest in the theory of the mind has origins and is useful in resolving problems of ethics; for the young Marshall, the theory of the mind is a prevalent interest, and is not useful in resolving problems different from those of a theory of human action.

The second incidental consideration concerns the modernity of Edgeworth's approach to probability. In the philosophy of science, at least starting from Rudolf Carnap, $^{24}$ a view of probability indicated with the term pluralism became manifest (Costantini-Geymonat 1982; Cohen 1989: 81-114) which was antithetical to dogmatism. The latter term refers to the theories which asserted that probability has a single and well-defined meaning, while all the other interpretations must be considered false: after an explicit definition of probability was introduced, all the principles and theorems were obtained from it. In this sense, both Laplace and Bruno De Finetti were

\footnotetext{
${ }^{24}$ Carnap (1950) distinguishes two different meanings of probability which are substantially unyielding, one from the other: the notion of the degree of confirmation of one hypothesis and that of statistical probability are indicated, respectively, as Probability ${ }_{1}$ and Probability ${ }_{2}$.
} 
dogmatic. Edgeworth, together with Antoine A. Cournot, Frank P. Ramsey, and Carnap, can instead be numbered among the anti-dogmatics, even if his anti-dogmatism was sui generis - he did not in fact refuse the idea of a unitary foundation for probability, considering that the theory continued to find its justification on the outside, in the notion of experience. Edgeworth's pluralism had its origin in the weakness of the external justification, which enabled him to avoid dogmatic positions, to give rise to a semiaxiomatic structuring of $\mathrm{TP}$, and to leave open the possibility of interpreting the values of probability subjectively.

Let us now come to the sense of the reconstruction presented in these pages within the framework of an overall interpretation of Edgeworth's thought. The perspective of his early works is clearly philosophical. In particular, as regards both ethics and probability and statistics, Edgeworth proceeded with analogous reasonings: he first asked himself about the foundations of the disciplines, the characteristics of the cognitive material on which to found the theory, and then studied their applications. Let us take ethics for example: after having defined the characteristics of pleasure, in NOME Edgeworth posed himself the problem of quantitatively defining the ultimate purpose of utilitarian ethics: "the greatest quantity of happiness of sentients". To this end, Edgeworth had at his disposal a definition of pleasure which enabled him to reduce human behaviour to its essentials; and permitted him to apply the instruments perfected by the psycho-physical tradition of Fechner and Wundt to utilitarian ethics. This is the first novel element: Edgeworth acquired the instruments of the most modern practices of psychological research, and applied them to a traditional philosophical discipline (ethics). The second novel element, discussed by Newman and Creedy (1986), was the introduction in NOME of new mathematical instruments (maximisation with Lagrange's multiplier). Both operations were based, however, on a thorough study of the founding notion of pleasure, the characteristics of which were connected to the conclusions of the theory.

As far as probability was concerned, the reasoning was completely analogous: after having discussed the foundations, Edgeworth studied the applications of the theory. The foundations gave him the limits within which his reasonings were correct. Edgeworth defined probability in such a way that it cannot be used either as a positive or as a normative criterion for choice under uncertainty (Baccini 2001, 2004). The more 
general idea behind this conclusion is that human action is not guided by epistemicaltype judgements - such as those furnished by probability. Instead, with several degrees of abstraction, it can be considered that it is guided by the search for pleasure. To facilitate the application of mathematics to the science of society, it can be hypothesised that man acts like a "pleasure machine” (Edgeworth 1881: 15). This does not give any indication regarding the real behaviour of concrete persons in the individual cases (like frequentist probability for single case), but makes it possible to grasp an average trend that is characteristic of the human species (like frequentist probability for series).

Edgeworthian probability, instead, lends itself very well to being utilised as an instrument of analysis for statistics. The psycho-physicists had introduced controlled experiments in the study of human behaviour, radically modifying the precepts of the discipline's scientific nature; in the social sciences, the possibility of controlled experiments is very reduced. The change would have come from the introduction of the diffusion of statistical methods based on probability. As Stephen M. Stigler showed (1986), Edgeworth made a central contribution to this diffusion. Edgeworth's statistics was no longer the deterministic one of Jevons or that of Marshall's red book. The central point - which is new in the panorama of the social sciences - becomes, "under what circumstances does a difference of figures correspond to a difference of fact?” (Edgeworth 1884C: 38). To adventure in this new direction, Edgeworth needed a theory of probability that was, so to speak, completely free of the narrow limits imposed by Venn. Edgeworth constructed it, and applied it extensively.

Within the general context of the historiography on Edgeworth, at this point we would need to reply to a central query. Why did Edgeworth prefer to occupy himself with probability and statistics, instead of continuing to work on topics of economics? The impression is that the question is ill-posed. During the fifteen-year period between 1875 and 1891, Edgeworth worked at building a series of new methods for the social sciences. These methods had at their basis a very well-defined common nucleus and very sound philosophical roots. What makes us see unexpected changes of direction in his programme of research is probably our habit of making a clear-cut separation among the disciplines. A careful analysis of his works within the perspective indicated in this paper can say how much his research programme was directed at the coherent application of "a single central idea". We hope to have demonstrated that this 
unitariness in Edgeworth's research programme is valid at least for the epistemological foundation of ethics and of probability.

\section{References}

BACCINI 1997

Baccini, A., "Edgeworth on the fundamentals of choice under uncertainty", History of Economic Ideas, 2: 7-31

BACCINI 2001

"Frequentist probability and choice under uncertainty", History of Political Economy, 33.4: 743-772 .

BACCINI 2003

"Bibliography of Edgeworth's writings", in Newman, P. (a cura di), F.Y. Edgeworth's Mathematical Psychics and Further Papers on Political Economy, Oxford, Oxfrod University Press: 621-647.

BACCINI 2004

"High pressure and black clouds: Keynes and the frequentist theory of probability", Cambridge Journal of Economics, forthcoming.

\section{BARRATT 1869}

Barratt, A., Physical Ethics, London, Williams \& Norgate.

BARRATT 1877

Barratt, A., "Ethics and Politics", Mind, 1: 453-476

CARNAP 1950

Carnap, R., Logical Foundations of Probability, Chicago, Chicago University Press, 1950.

\section{COHEN 1989}

Cohen, L.J., An Introduction to the Philosophy of Induction and Probability, Oxford, Clarendon Press.

COSTANTINI-GEYMONAT 1982

Costantini, D., Geymonat, L., Filosofia della probabilità, Milano, Feltrinelli.

\section{CREEDY 1986}

Creedy J., Edgeworth and the Development of Neoclassical Economics, London, Basil Blackwell.

DESSÌ 1988

Dessì, P., L'ordine e il caso. Discussioni epistemologiche e logiche sulla probabilità da Laplace a Peirce, Bologna, Il Mulino. 
Edgeworth, F.,Y., “Mr. Matthew Arnold on Butler's doctrine of self-love”, Mind, I: 570-571

\section{EDGEWORTH 1877 (NOME)}

Edgeworth, F.,Y., New and Old Methods of Ethics, or «Physical Ethics», London, Parker \& co., 1877.

\section{EDGEWORTH 1879}

Edgeworth, F., Y., “The hedonical calculus”, Mind, 1879, IV: 394-408

\section{EDGEWORTH 1881}

Edgeworth, F.,Y., Mathematical Psychics, London, Kegan Paul \& Co (photographic reprint London, LSE 1932)

EDGEWORTH 1883

Edgeworth, F., Y., "The physical basis of probability", Philosophical Magazine, XVI: 433-435

\section{EDGEWORTH 1884}

Edgeworth, F.,Y., "The philosophy of chance", Mind: 223-235.

\section{EDGEWORTH 1884A}

Edgeworth, F.,Y., "A priori probabilities", Philosophical Magazine: 204-210.

\section{EDGEWORTH 1884B}

Edgeworth, F., Y., "Chance and law", Hermathena: 154-163.

\section{EDGEWORTH 1884C}

Edgeworth, F., Y., Review of Jevons, W.S., Investigations in Currency and Finance, Academy, June 19, 637: 38-39

\section{EDGEWORTH 1888}

Edgeworth, F.,Y., "The mathematical theory of banking”, Journal of the Royal Statistical Society, 1888, LI: 113-127

\section{EDGEWORTH 1888A}

Edgeworth, F.,Y., "Review of Venn, J., The Logic of Chance", Journal of Education, May 1 1888: 251.

\section{EDGEWORTH 1889}

Edgeworth, F.,Y., "Points at which mathematical reasoning is applicable to political economy (Opening address of the President to Section F of the British Association)", Nature 40: 496-509.

\section{EDGEWORTH 1891}

Edgeworth, F.,Y., "Osservazioni sulla teoria matematica dell'economia politica con riguardo speciale ai principi di economia di Alfredo Marshall”, Giornale degli economisti, II, 2: 233-245. 


\section{EDGEWORTH 1891A}

Edgeworth, F.,Y., Ancora a proposito della teoria del baratto, Giornale degli economisti , II, 3: 316-318. [English Translation and abridgement in PRPE, On the determinatess of economic equilibrium, II: 313-319] [Reply to Arthur Berry "Alcune brevi parole sulla teoria del baratto di A. Marshall”, Giornale degli economisti, 1891, I: 549-553.]

\section{EDGEWORTH 1899}

Edgeworth, F.,Y., "Probability" in Palgrave, R.H.I. (ed.), Dictionary of Political Economy, London, Macmillan and Co., vol. III: 208.

\section{EDGEWORTH 1908}

Edgeworth, F.,Y., "On the probable errors of frequency constants", Journal of the Royal Statistical Society, 1908: 381-397, 499-512, 651-661, 662-678; 1909: 81-90.

\section{EDGEWORTH 1911}

Edgeworth, F.,Y., "Probability" in Encyclopaedia Britannica, XIth ed., 1911: 376-403.

\section{EDGEWORTH 1921}

Edgeworth, F.,Y., "Molecular statistics”, Journal of the Royal Statistical Society, LXXXIV: 71-89.

\section{EDGEWORTH 1922}

Edgeworth, F.,Y., "The philosophy of chance", Mind, 1922: 257-283.

EDGEWORTH 1922A

Edgeworth, F.,Y., "Molecular statistics”, Journal of the Royal Statistical Society, LXXXV: 479-487

\section{HOWEY 1960}

Howey, R.S., The Rise of the Marginal Utility School 1870-1889, Lawrence, University of Kansas Press (reprinted Columbia Univeristy Press 1989).

\section{LAPLACE 1814}

Laplace, P.S., Essai Philosophique sur les Probabilités, Paris, 1814 (citation from the sixth edition of 1840)

\section{LAPLACE 1886}

Laplace, P.S., Théorie analytique des Probabilités, in Evres complètes de Laplace, Paris, Gauthiers-Villars, vol. 7, 1886.

\section{LECALDANO 1995}

Lecaldano, E., "Etica" in Rossi, P., (ed.), La filosofia. Volume terzo: Le discipline filosofiche, Torino, Utet: 323-436

\section{MCCANN 1996}

McCann, C.R., "Introduction: Edgeworth's contributions to probabilità and statistics" in McCann, C.R. (ed.), F.Y. Edgeworth: Writings in Probability, Statistics and Economics, Cheltenham, Edward Elgar: xi-xxv. 


\section{MIROWSKI 1994}

Mirowski, P., "Marshalling the Unruly Atoms: Understanding Edgeworth's Career", in IDEM (ed.), Edgeworth on Chance, Economic Hazard and Statistics, Lanham, Rowman \& Littlefield Publishers, 1994.

\section{NEWMAN 1987}

Newman, P., "Edgeworth, Francis Ysidro" in Eatwell, J., Milgate, M., Newman, P. (eds.), The New Palgrave: A Dictionary of Economics, London, MacMillan vol. II: 8498.

\section{PEARSON 1900}

Pearson, K., Grammar of Science, London, Walter Scott, $1900^{2}$.

\section{PeARson 1900A}

Pearson, K., "On the criterion that a given system of deviations from the probable in the case of a correlated system of variables is such that it can be reasonably supposed to have arisen from random sampling”, Philosophical Magazine, 50: 157-175

\section{PEARson 1906}

Pearson, K., “Walter Frank Raphael Weldon”, Biometrika, 5: 1-50.

PORTER 1986

Porter, T.M., The Rise of Statistical Thinking 1820-1900, Princeton, Princeton University Press.

PROCTOR 1874

Proctor, R.A., The Universe and the Coming Transits, London.

\section{RAFFAELLI 2003}

Raffaelli, T., Marshall’s Evolutionary Economics, London e New York, Routledge.

\section{SHANKS 1853}

Shanks, W., Contributions to Mathematics, Comprising Chiefly the Rectification of the Circle to 607 Place of Decimals, London.

\section{SIDGWICK 1874}

Sidgwick, H., The Methods of Ethics, London, MacMillan \& Co..

\section{SPENCER 1870}

Spencer, H., The Principles of Psychology, second edition, London, William \& Norgate, 1870.

\section{STIGLER 1986}

Stigler, S.M., The History of Statistics, Cambridge (Mass.) and London, Belknap Press.

\section{SULLY 1918}

Sully, J., My Life and Friends, New York, E.P. Dutton and Co.

\section{VENN 1888}

Venn, J., The Logic of Chance, London, Macmillan, 1888. 